University of Nebraska - Lincoln

DigitalCommons@University of Nebraska - Lincoln

10-10-2019

\title{
Phenotypically Plastic Responses to Predation Risk Are Temperature Dependent
}

Thomas M. Luhring

University of Nebraska - Lincoln, tomluhring@gmail.com

Janna M. Vavra

University of Nebraska - Lincoln, janna@unl.edu

Clayton E. Cressler

University of Nebraska-Lincoln, ccressler2@unl.edu

John DeLong

University of Nebraska - Lincoln, jpdelong@unl.edu

Follow this and additional works at: https://digitalcommons.unl.edu/bioscifacpub

Part of the Animal Experimentation and Research Commons, and the Biology Commons

Luhring, Thomas M.; Vavra, Janna M.; Cressler, Clayton E.; and DeLong, John, "Phenotypically Plastic Responses to Predation Risk Are Temperature Dependent" (2019). Faculty Publications in the Biological Sciences. 754.

https://digitalcommons.unl.edu/bioscifacpub/754

This Article is brought to you for free and open access by the Papers in the Biological Sciences at DigitalCommons@University of Nebraska - Lincoln. It has been accepted for inclusion in Faculty Publications in the Biological Sciences by an authorized administrator of DigitalCommons@University of Nebraska - Lincoln. 


\title{
Phenotypically plastic responses to predation risk are temperature dependent
}

\author{
Thomas M. Luhring, ${ }^{1,2}$ Janna M. Vavra, ${ }^{1}$ \\ Clayton E. Cressler, ${ }^{1} \&$ John P. DeLong ${ }^{1}$ \\ 1 School of Biological Sciences, University of Nebraska- Lincoln, \\ 410 Manter Hall, Lincoln, NE 68588, USA \\ 2 Present address - Department of Biological Sciences, Wichita State \\ University, 1845 Fairmount Street, Wichita, KS 67260, USA \\ Corresponding author — Thomas M. Luhring, tomluhring@gmail.com
}

\begin{abstract}
Predicting how organisms respond to climate change requires that we understand the temperature dependence of fitness in relevant ecological contexts (e.g., with or without predation risk). Predation risk often induces changes to life history traits that are themselves temperature dependent. We explore how perceived predation risk and temperature interact to determine fitness (indicated by the intrinsic rate of increase, $r$ ) through changes to its underlying components (net reproductive rate, generation time, and survival) in Daphnia magna. We exposed Daphnia to predation cues from dragonfly naiads early, late, or throughout their ontogeny. Predation risk increased $r$ differentially across temperatures and depending on the timing of exposure to predation cues. The timing of predation risk likewise altered the temperature-dependent response of $T$ and $R_{0}$. Daphnia at hotter temperatures responded to predation risk by increasing $r$ through a combination of increased $R_{0}$ and decreased $T$ that together countered an increase in mortality rate. However, only $D$. magna that experienced predation cues early in ontogeny showed elevated $r$ at colder temperatures. These results highlight the fact that phenotypically plastic responses of life history traits to predation risk can be strongly temperature dependent.
\end{abstract}

Keywords: Climate change, Fecundity, Life history, Mortality, Reproduction, Survivorship

Published in Oecologia (2019); doi 10.1007/s00442-019-04523-9

Submitted 7 September 2018; accepted 30 September 2019; published 10 October 2019.

Copyright ( 2019 Springer-Verlag GmbH Germany. Used by permission.

Supplementary material follows the References. 


\section{Introduction}

Global climate change is leaving an indelible mark on the ecology of organisms worldwide (Walther et al. 2002; Parmesan 2006; Poloczanska et al. 2013). Organisms can respond to climate change through rapid evolutionary and/ or developmental changes in morphology, behavior, and life history (Reale et al. 2003; Knies et al. 2006, 2009; Charmantier et al. 2008; Angilletta et al. 2010; Anderson et al. 2012; Charmantier and Gienapp 2014; Tseng and O'Connor 2015; Seebacher et al. 2015; Padfield et al. 2016; Schaum et al. 2017). Furthermore, changing thermal regimes associated with climate change influence virtually all aspects of natural systems, because biological processes are dominated by the effects of temperature (Ernest et al. 2003; Brown et al. 2004; Kerkhoff et al. 2005; Kingsolver 2009; DeLong et al. 2017). While the temperature dependence of fitness is of interest for projecting the effects of climate change (Deutsch et al. 2008; Vasseur et al. 2014; Sinclair et al. 2016), the traits that determine fitness occur within the context of natural food webs and are simultaneously altered and constrained by temperature and other factors (e.g., predation, allocation trade-offs) (Luhring et al. 2018).

Predation and predation risk strongly influence prey evolution, development, morphology, behavior, and life history (Reznick and Endler 1982; Lima and Dill 1990; Stibor 1992; Van Buskirk and Schmidt 2000; Benard 2004; Lind and Cresswell 2005; Grigaltchik et al. 2012, 2016; Seebacher and Grigaltchik 2015; Tseng and O'Connor 2015; Luhring et al. 2016). Furthermore, predators shape prey demography and dynamics through both the lethal effects of predation and the effects of predation risk on prey behavior and phenotypes (Pangle et al. 2007; Creel and Christianson 2008; Zanette et al. 2011). Prey can respond to changes in their perceived likelihood of mortality (e.g., environmental conditions, predation risk) by altering the timing of and effort put into reproduction (Roitberg et al. 1993; Beckerman et al. 2007, 2010). Although there are myriad studies of how life histories change with temperature or predation risk (Riessen 1999; Atkinson et al. 2001; Benard 2004; Angilletta 2009; Walsh et al. 2014), only a few recent studies investigate their combined effects across a temperature gradient (Katzenberger et al. 2014; Culler et al. 2014; Seebacher and Grigaltchik 2015; Grigaltchik et al. 2016; Luhring and DeLong 2016; Luhring et al. 2018). 
Changes in fitness with temperature can provide promising insight into the long term effects of climate change (Lynch and Gabriel 1987; Gilchrist 1995; Angilletta 2009; Sinclair et al. 2016). For example, the temperature dependence of fitness has been used to predict the effects of different potential future climates (Deutsch et al. 2008; Vasseur et al. 2014; Sinclair et al. 2016). This approach uses thermal performance curves (TPCs) (a reaction norm) to measure the nonlinear effect of temperature on fitness (Angilletta 2009; Kingsolver 2009). However, an implicit assumption of this work is that the TPC for a given species is a robust indicator of the thermal dependence of fitness in all ecological settings (Angilletta 2009; Sinclair et al. 2016). This assumption of TPC immutability is contradicted by clear changes in TPCs due to evolution (Padfield et al. 2016; Schaum et al. 2017), latitude (DeLong et al. 2018), previous thermal exposure (Schulte et al. 2011; Seebacher et al. 2015; Luhring and DeLong 2017; Kremer et al. 2018), nutrient limitation (Thomas et al. 2017), and responses to predation risk (Luhring and DeLong 2016).

Here, we focus on how predation risk alters TPCs to elucidate how responses to ecological context vary with temperature. To understand the temperature dependence of responses to predation risk, we must be able to first account for the underlying nonlinear response of life history traits to temperature. There are three general ways in which predation (or any ecological factor) can change trait TPCs (see Schulte et al. 2011). (1) a vertical shift whereby the trait is increased or decreased equally across all temperatures, indicating that predation has a temperature-independent effect on the entire curve (Fig. 1a); (2) a horizontal shift whereby the underlying temperature dependence of the trait is shifted hotter or colder, but the shape of the TPC is not altered, indicating that predation causes acclimation of the trait to a new temperature (Fig. 1b); or (3) a change in the shape of the TPC whereby there is an unequal effect of predation risk on the trait across temperatures, indicating that predation has a temperature-dependent effect (Fig. 1c).

$R_{0}$ and $r$ differ in their underlying temperature dependence (Huey and Berrigan 2001) and their suitability as a measure of fitness given ecological and demographic contexts (Roff 1992). The widely used intrinsic rate of population increase $(r)$ integrates the effects of key life history traits (age at reproduction, fecundity, survival) with respect to time (Roff 1992). As such, it is a useful measure for integrating the 


\section{A Vertical Shift}
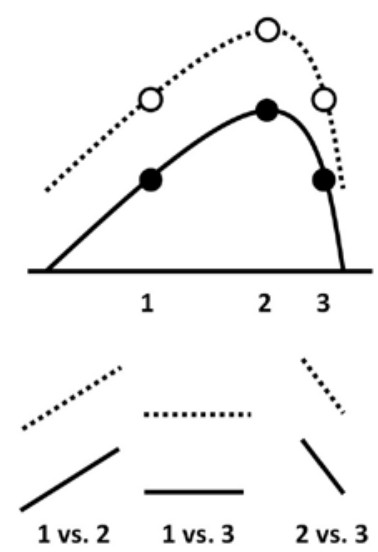

B Horizontal Shift
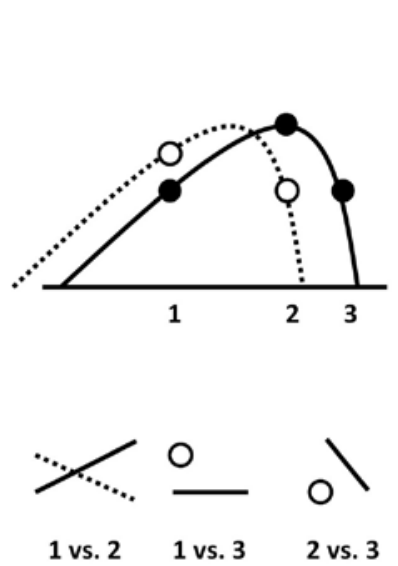

1 vs. 2 vs. 3
C Shape Change
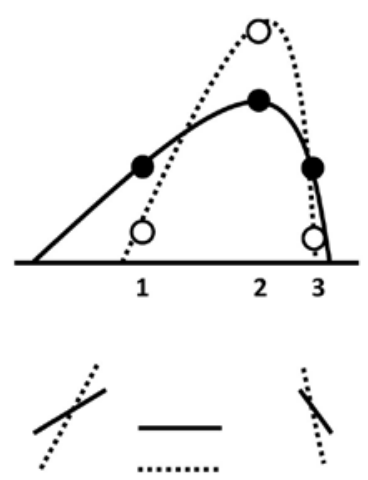

1 vs. 2 vs. $3 \quad 2$ vs. 3

Fig. 1. Changes to a thermal performance curve (TPC) caused by response of a trait (e.g., $r$ ) to change in ecological context (e.g., predation). Trait $r$ TPCs without predation risk (solid black line and filled circles) can shift vertically (a) if predation causes a consistent increase across all temperatures, (b) shift the TPC horizontally, or (c) change the actual shape of the TPC if the effects of predation on $r$ are dependent on temperature (i.e., predation does not have a consistent effect across temperature). The bottom row highlights perceived temperature-dependent patterns that arise from measuring the nonlinear TPC at two discrete points (e.g., temperature 1 vs. 2,1 vs. 3, or 2 vs. 3). Within each example (a-c), three different outcomes are seen in the perceived temperature dependence of the two curves and their interactions that are wholly dependent on the temperatures selected for comparison.

combined effects of predation risk and temperature which alters not only reproductive effort but also the timing of reproductive events (Stibor 1992; Beckerman et al. 2007). We measured how predation risk affected $r$, net reproductive rate $\left(R_{0}\right)$, generation time $(T)$, and survival $(S)$ of a clonal population of Daphnia magna across a range of temperatures. Daphnia is an ecologically important freshwater consumer with life histories that show plastic responses to temperature and predation risk (Riessen 1999; Giebelhausen and Lampert 2001; Luhring et al. 2018). We also tested the temperature dependence of trait responses to predation risk experienced before and after maturation (first clutch), because phenotypically plastic responses change across ontogeny (Hoverman and Relyea 2007) and predation risk in natural environments varies across time and space (Tolon et al. 2009).

We raised $D$. magna at seven temperatures ranging from 11 to 33 ${ }^{\circ} \mathrm{C}$ under four different predation risk treatments that varied in the 
timing of exposure to predation risk during ontogeny: (1) control (no risk cues), (2) early exposure (risk cues from day 1 to 7), (3) late exposure (risk cues from day 7 to 21), and (4) constant exposure (risk cues from day 1 to 21). Late and early predation exposure treatments allowed us to investigate the temperature dependence of phenotypically plastic responses to predation risk that were experienced prior to or immediately after their first clutch. Daphnids respond to predation risk from non-gape-limited predators by decreasing time to reproduction (increased likelihood of reproducing prior to being consumed) and or increasing the number of offspring they produce per clutch (increased likelihood that at least one offspring will survive to reproduction) (Stibor and Luning 1994; Reede 1995; Sakwińska 1998; Riessen 1999; Luhring et al. 2018). Predator-induced phenotypically plastic changes in $r$ are the outcome of changes in life history traits that have varying responsiveness to predation risk (Boersma et al. 1998), and are both temperature dependent and connected through temperature-dependent trade-offs (Luhring et al. 2018). Thus, we predict that while $D$. magna will respond to predation risk by increasing $r$, their ability to elevate $r$ will vary across temperature (e.g., Fig. 1c). Furthermore, we expect this response will be the consequence of temperature-dependent effects of predation risk on the underlying traits $T, R_{0^{\prime}}$ and $S$.

\section{Methods and materials}

\section{Study organism and husbandry}

Prior to the experiment, D. magna clonal stocks (originally isolated from Kaimes Farm, Leitholm, Scottish Borders, $2^{\circ} 20^{\prime} 43^{\prime \prime} \mathrm{W}, 55^{\circ} 42^{\prime} 15^{\prime \prime} \mathrm{N}$ ) were maintained at $17^{\circ} \mathrm{C}$ on a $16: 8$ light:dark cycle and fed Chlamydomonas reinhardtii (CPCC 243) at $0.1 \mathrm{mg} \mathrm{C} / \mathrm{mL}$. To standardize maternal effects, individual $D$. magna were maintained under the above conditions for three generations after which third brood neonates were collected within $24 \mathrm{~h}$ of birth and assigned at random to experimental treatments. During the experiment, $D$. magna were maintained in $30 \mathrm{~mL}$ glass vials containing $25 \mathrm{~mL}$ of COMBO (absent of nitrates and phosphates to control for bacterial contamination), a standardized media for Daphnia husbandry (Kilham et al. 1998). 


\section{Predator cue production}

A mixed species community of odonates (mostly libellulids) were collected from a nearby freshwater pond on the Spring Creek Audubon Center in southeastern Nebraska (Novich et al. 2014; Luhring and DeLong 2016). Prior to the experiment, a mixed age-size stock of $D$. magna $(N=340)$ were placed in $2.04 \mathrm{~L}$ of COMBO media with odonates ( $N=17, \sim 10-15 \mathrm{~mm}$ total length) for $24 \mathrm{~h}$. Odonates consumed nearly all $D$. magna provided to them while presumably producing a variety of olfactory cues consistent with predation events (e.g., kairomones, alarm cues). After the $24 \mathrm{~h}$ period, the cue-laden COMBO (hereafter "cue") was filtered through $63 \mu \mathrm{m}$ sieves to removed particulate matter (e.g., feces, molts). All cue produced during the $24 \mathrm{~h}$ period ( $\sim 4-5$ replicate containers) was then combined into a single batch and gently mixed prior to being frozen in $50-200 \mathrm{~mL}$ aliquots to prevent cue degradation (Hickman et al. 2004; Crawford et al. 2012; Luhring et al. 2016). Three such $24 \mathrm{~h}$ batches of cue were produced prior to the experiment. When cue was needed for the experiment, equal amounts of cue from each of the three batches was thawed in lukewarm water baths prior to being combined in a master mix for distribution among the vials. By replacing the predation cue during every water change (see below), Daphnia in predation risk treatments experienced fresh pulses of cue three times a week.

\section{Husbandry and measurements during experiment}

Water changes (new COMBO and predation cues) were conducted every Monday, Wednesday and Friday over the course of the experiment (day $1=$ Monday). Each experimental vial was filled with $25 \mathrm{~mL}$ of COMBO (either with or without cue) combined with algae to reach $0.1 \mathrm{mg} \mathrm{C} / \mathrm{mL}$. To get algal concentration estimates prior to adding to vials, we created a dilution series, took fluorometer measurements and calculated the dry weight of the algae across the dilution series. We used $50 \%$ of the dry mass as a $C$ estimate to then regress fluorometry readings with $C$ content and then used those readings to calculate how much of that day's algal culture was needed to bring the 25 $\mathrm{mL}$ of $\mathrm{COMBO}$ to $0.1 \mathrm{mg} \mathrm{C} / \mathrm{mL}$. Within each vial, algae were added into $5 \mathrm{~mL}$ of COMBO prior to adding $20 \mathrm{~mL}$ of COMBO with or without alarm cue (depending on treatment). All vials were acid washed 
and oven dried between transfers to prevent transfer of predator cues among treatments. The experiment was conducted in $24 \mathrm{~h}$ dark to prevent algae from growing, thereby limiting differences in algal $C$ across the treatments.

\section{Experimental design}

To assess the temperature dependence of phenotypically plastic responses to predation risk with respect to the timing of exposure during ontogeny, the experiment took place over two discrete intervals: (1) a "natal" period (days 1-7) and (2) a "TPC" period (days 7-21). During the natal period, all $D$. magna were maintained in $24 \mathrm{~h}$ dark at 17 ${ }^{\circ} \mathrm{C}$ across seven environmental chambers (Percival Intellus Ultra Control System). The natal period at $17^{\circ} \mathrm{C}$ allowed us to incorporate the effects of temperature across a wider range of temperatures as individuals raised at high or low temperatures from their birth would have either failed to reach maturity during the experiment (colder temperatures) or failed to survive to reproduce (hotter temperatures). Furthermore, the extended acclimation during the natal period allowed us to isolate the effects of predation risk on $r, R_{\alpha} T$, and $P$. After water changes on day 7 , the TPC period began and the seven environmental chambers were set to $11,17,23,27,29,31$, or $33^{\circ} \mathrm{C}$ (chambers were randomly assigned temperatures). Treatments varied in the timing of exposure to predation cues: (1) Control-no predation cue during natal or TPC periods, (2) Early-exposure to predation cue during natal period only, (3) Late-exposure to predation cues during TPC period only, and (4) Constant-exposure to predation cues during both the natal and TPC periods. Each treatment was replicated ten times within each environmental chamber with each replicate being a single Daphnia magna housed in a $30 \mathrm{~mL}$ glass vial.

Daphnia magna were observed daily until broods were close to being born (day 8), after which they were checked twice daily for births and deaths on non-water change days (30 checks over 21 days). Clutch sizes were collected on water change days to minimize and standardize handling of adults. Offspring appearing in vials in successive days were combined into a single clutch and given the earliest observed birth date. 


\section{Data analysis}

We calculated life history traits from measurements of survival and fecundity through time. Each day $(x)$, we recorded whether each $D$. magna was alive and the number of offspring it produced since the last time point. We then estimated age-specific survivorship $\left(l_{x}\right)$ (fraction of the initial number of individuals still alive at each time step) and age-specific fecundity $\left(m_{x}\right)$ (average number of offspring born to a mother at each time step). Values of $l_{x}$ and $m_{x}$ were estimated independently within each treatment-by-temperature combination. Net reproductive rate $\left(R_{0}\right)$, generation time $(T)$, and intrinsic rate of increase $(r)$ were calculated from $l_{x}$ and $m_{x}$ across the entire time period as follows (Stearns 1992):

$$
\begin{gathered}
R_{0}=\sum l_{x} m_{x} \\
T=\sum\left(x \cdot l_{x} m_{x}\right) / R_{0} \\
r=\ln \left(R_{0}\right) / T
\end{gathered}
$$

Since this procedure would only produce single estimates of $l_{x^{\prime}}$ $m_{x^{\prime}} R_{0^{\prime}} T$, and $r$, we used bootstrapping to generate confidence intervals for these parameters. Specifically, at each time step $(x)$ for each treatment-by-temperature combination, we resampled the individuals with replacement 1000 times (creating 1000 bootstrapped "populations" the same size as the starting population). We then computed $l_{x^{\prime}} m_{x^{\prime}} R_{0^{\prime}} T$, and $r$ for this resampled population to generate confidence intervals.

In addition to measuring group-wise average age-specific survivorship $\left(l_{x}\right)$ as described above, we also analyzed individual survivorship (S) during the TPC period using Cox proportional hazard models (Cox 1972) $(N=249)$. For Cox proportional hazard models, only individuals that were alive at the start of the TPC period were used in the analyses.

We analyzed the effects of temperature and predation cue on bootstrapped estimates of $R_{\sigma}, T$, and $r$ with Generalized Additive Models (GAMs) (Wood 2006) to account for the nonlinear effects of temperature (Kingsolver 2009; Amarasekare and Savage 2012; 
DeLong et al. 2017). We created GAMs with the 'gam' function with cubic regression splines ('mgcv' package) (Wood 2006, 2015; R Core Team 2018). Each GAM was created with a temperature term with a smoother and a treatment term that included a temperature smoother. The smoother term in the temperature term accounts for the nonlinear effects of temperature across treatments (i.e., the experiment-wide TPC) whereas the temperature smoother within the treatment effect accounts for treatment-specific temperature dependence (i.e., deviations in shape from the experiment- wide TPC). This approach allowed us to analyze all treatments together while accounting for the possibility that they each have different TPCs. Temperature smooth terms were initially set to three knots and treatment-specific temperature smoothers were set to three knots. We checked GAMs with the 'gam.check' function and by plotting residuals prior to analysis through 'anova.gam' and 'summary.gam' ('mgcv' package). Only the GAM for $r$ required an increase in the number of knots in the temperature term $(k=5)$. The increased number of knots needed for the $r$ TPC temperature smooth term appeared to be caused by a highly accelerated increase and decrease in $r$ between 23 and $33{ }^{\circ} \mathrm{C}$. All other GAM smoothers were sufficient at three knots (representing the simplest possible GAM).

We estimated effects of predation treatment and temperature on survivorship $(S)$ with Cox proportional hazard models using the 'coxph' function in the R package "survival" (Therneau and Lumley 2017). Our initial model testing for the effects of temperature, treatment and their interaction on survivorship indicated a significant interaction between temperature and treatment (Temperature:Treatment $\chi^{2}=17.7$, d.f. $=3, P=0.0005$ ). This appeared to be driven by uniformly low mortality in the $11,17,23$, and $27^{\circ} \mathrm{C}$ groups. Analysis of this subset of temperatures showed that there were neither temperature $\left(\chi^{2}=1.65\right.$, d.f. $\left.=1, P=0.20\right)$ nor treatment $\left(\chi^{2}=6.78\right.$, d.f. $\left.=3, P=0.08\right)$ effects on survivorship curves. Each of the remaining three temperatures $\left(29,31\right.$, and $\left.33^{\circ} \mathrm{C}\right)$ was analyzed separately with 'coxph' with treatment as a predictor of survivorship. We then analyzed each single-temperature Cox proportional hazard model with a post hoc Tukey test with the ' $g l h t^{\prime}$ function in the R package "multcomp" (Hothorn et al. 2017). 


\section{Results}

\section{Net reproductive rate}

Net reproductive rate $\left(R_{0}\right)$ showed a strong unimodal response to temperature with a peak at intermediate temperatures $\left(\sim 17-27^{\circ} \mathrm{C}\right)$ (Fig. 2). Constant exposure to predation risk cues across ontogeny elevated $R_{0}$ consistently across temperature, resulting in a phenotypically plastic and temperature-independent increase in $R_{0}$ (Table S1) (Fig. 2). However, when predation risk was present only in the early or late parts of ontogeny, phenotypically plastic responses of $R_{0}$ were temperature dependent (non-constant effect of predation risk on $R_{0}$ across temperature) (Table S1) (Fig. 2). These temperature-dependent responses manifested as cold-elevated $R_{0}$ in early cue and hot-elevated $R_{0}$ in the late cue treatments. At $11^{\circ} \mathrm{C}, R_{0}$ was nearly three times

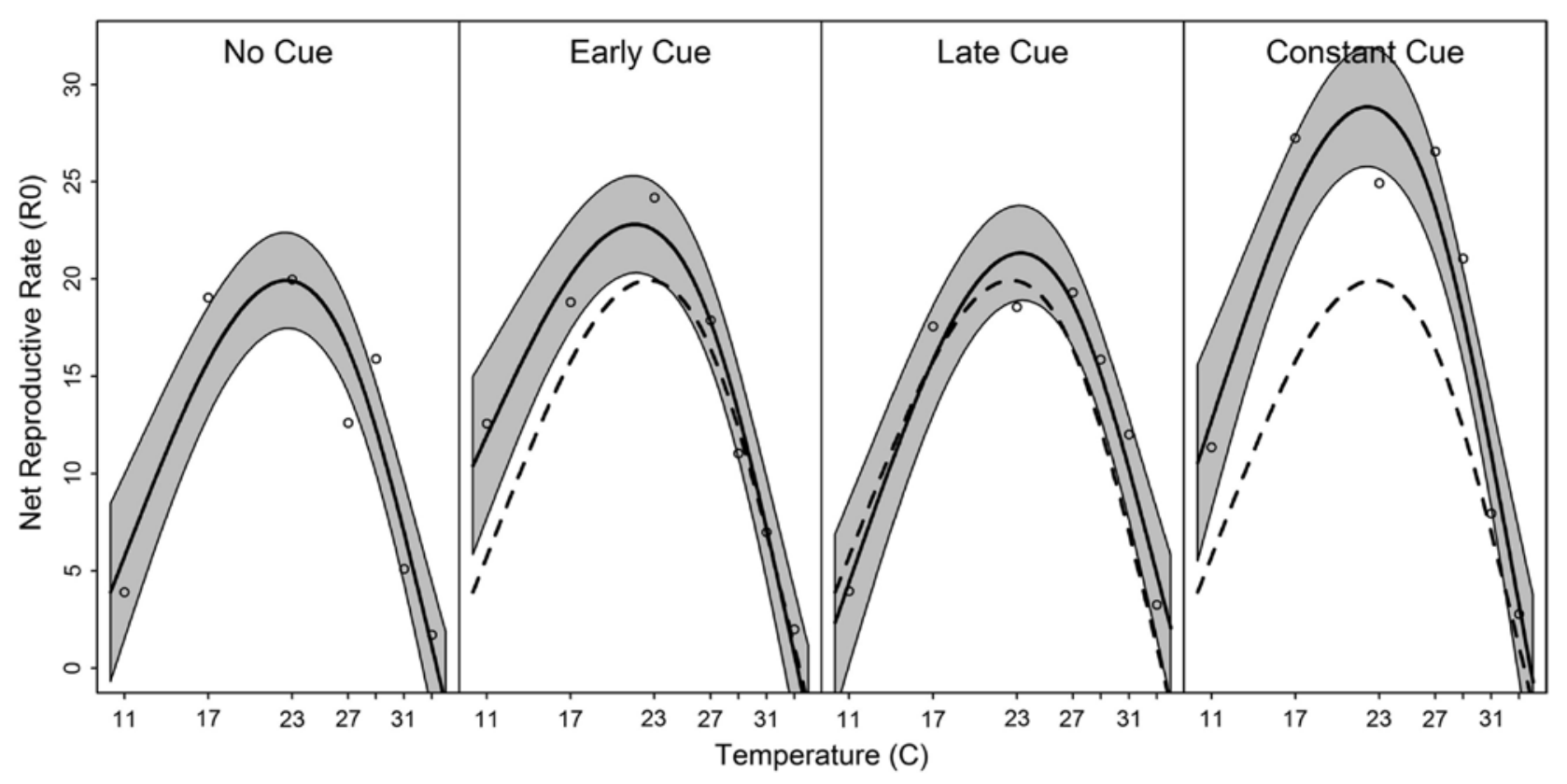

Fig. 2. Temperature dependence of net reproductive rate, $R_{0^{\prime}}$ by predation exposure treatment. Each point depicts the mean of 1000 bootstrapped populations drawn from 10 replicate $D$. magna resampled with replacement. Curves are predicted model fits from a GAM that incorporates both nonlinear temperature effects and treatment-specific temperature curves (GAM constructed from the entire dataset). Predation cues were presented prior to the assay temperature (Early), during the assay temperature (Late), or during both prior to and during the assay temperature (Constant). The fit from the No Cue (control) treatment is provided as a reference (dashed line) on the three treatments receiving predation cues. 
higher in treatments that were exposed to predation risk cues in the natal period (days 1-7) (early cue; 12.6, 8.6-17.5; bootstrap estimate, $95 \% \mathrm{Cl}$ ) (constant cue; $11.4,8.9-13.9)$ than treatments that did not (control; 3.9, 1.0-7.7) (late cue; 4.0, 1.4-6.9). Conversely, $R_{0}$ was higher at warmer temperatures in treatments where $D$. magna were exposed to cue later in ontogeny (late, constant cue) (Fig. 2). Although constant cue elevated $R_{0}$ in both the colder and warmer portions of the curves in a manner consistent with the early and late cue treatments, respectively, it also induced consistently increased $R_{0}$ at intermediate temperatures $\left(17-29^{\circ} \mathrm{C}\right)$ (Fig. 2).

\section{Generation time}

Generation time ( $T$ ) generally decreased with temperature (Fig. 3). Exposure to predation cues during the natal period resulted in shorter

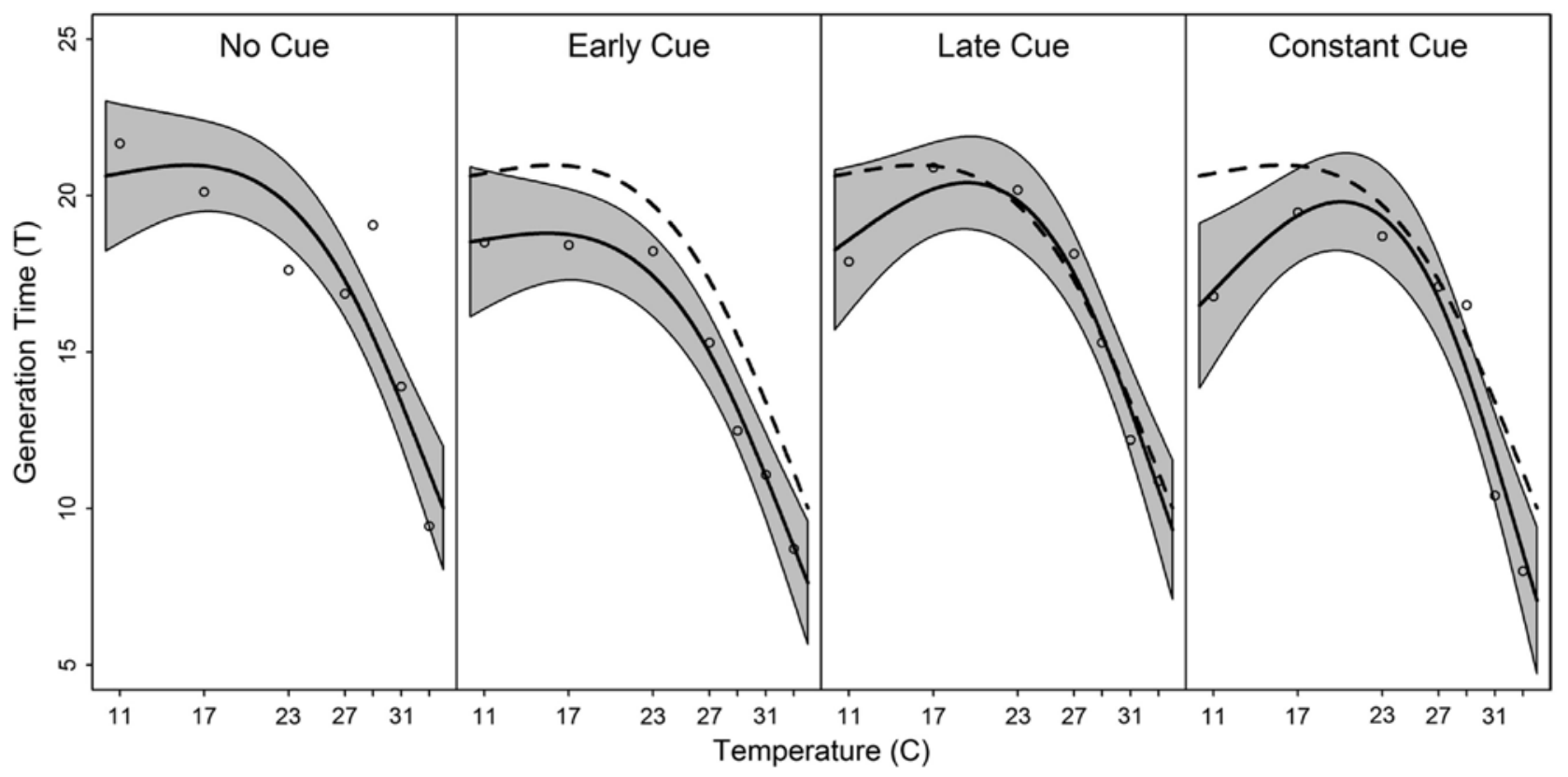

Fig. 3. Temperature dependence of generation time, $T$, by predation exposure treatment. Each point depicts the mean of 1000 bootstrapped populations drawn from 10 replicate $D$. magna resampled with replacement. Curves are predicted model fits from a GAM that incorporates both nonlinear temperature effects and treatment-specific temperature curves. Predation cues were presented prior to the assay temperature (Early), during the assay temperature (Late), or during both prior to and during the assay temperature (Constant). The fit from the No Cue (control) treatment is provided as a reference (dashed line) on the three treatments receiving predation cues. 
overall generation times for the early and constant treatments (Table S1; Fig. 3). The control and early treatments had marginally significant treatment-specific temperature smooth terms $(P<0.1)$, which appeared to be related to their relatively more monotonic decrease across temperature (compared to a potentially more unimodal response in late and constant cue treatments). All treatments exposed to predation risk had shorter average generation times at $11^{\circ} \mathrm{C}$ (Early: 18.5, 16.3-20.8; Late: 17.9, 16.2-20.0; Constant: 16.8, 15.7-18.0 days; bootstrap estimate, $95 \% \mathrm{Cl})$ than the control $(21.7,18.4-24.4)$.

\section{Intrinsic rate of increase}

The three treatments exposed to predation risk generally had higher overall population growth rates ( $r$ ) (Table S1). The shape of the relationship between temperature and $r$ changed depending on when D. magna were exposure to predation risk, indicating a temperaturedependent phenotypically plastic response to predation risk in $r$. The temperature smooth term most closely follows the early and constant cue (non-significant treatment-specific temperature smooth terms), whereas smooth terms of control and late cue treatments had different shapes from the early and constant treatment (Table S1) (e.g., Figs. $1 \mathrm{c}$ and 4). The strong peak of the late cue at hotter temperatures relative to colder temperatures most likely led to its smooth term significance.

As seen with $R_{0}$ only $D$. magna exposed to predation risk cue during early ontogeny had higher $r$ at colder temperatures (Fig. 4). Predation risk at any point in their ontogeny resulted in higher $r$ at warmer temperatures $\left(27-31^{\circ} \mathrm{C}\right)$, whereas predation risk during the TPC period (late and constant treatments) elevated $r$ at the hottest temperature $\left(33^{\circ} \mathrm{C}\right)$. The slightly bi-modal TPCs produced by $r$ GAM fits appears to be an artifact caused using all the treatments to fit the data when $r$ peaks at cooler temperatures $\left(T_{\text {opt }}\right)$ in the control treatment compared to the three predation treatments (Fig. 4). Because of the fitting artifact for $r$ curves, we report the highest observed estimates of $r\left(r_{\max }\right)$ from bootstrap estimates and associated temperature $\left(T_{\text {opt }}\right)$. Control $D$. magna showed a lower $r_{\text {max }}(0.170,0.153-0.185)$ at a colder temperature $\left(23^{\circ} \mathrm{C}\right)$ than early $\left(r_{\max }=0.192,0.134-0.245\right)$, late $\left(r_{\max }=0.203\right.$, $0.152-0.246)$, and constant predation risk $\left(r_{\max }=0.195,0.105-0.268\right)$ 


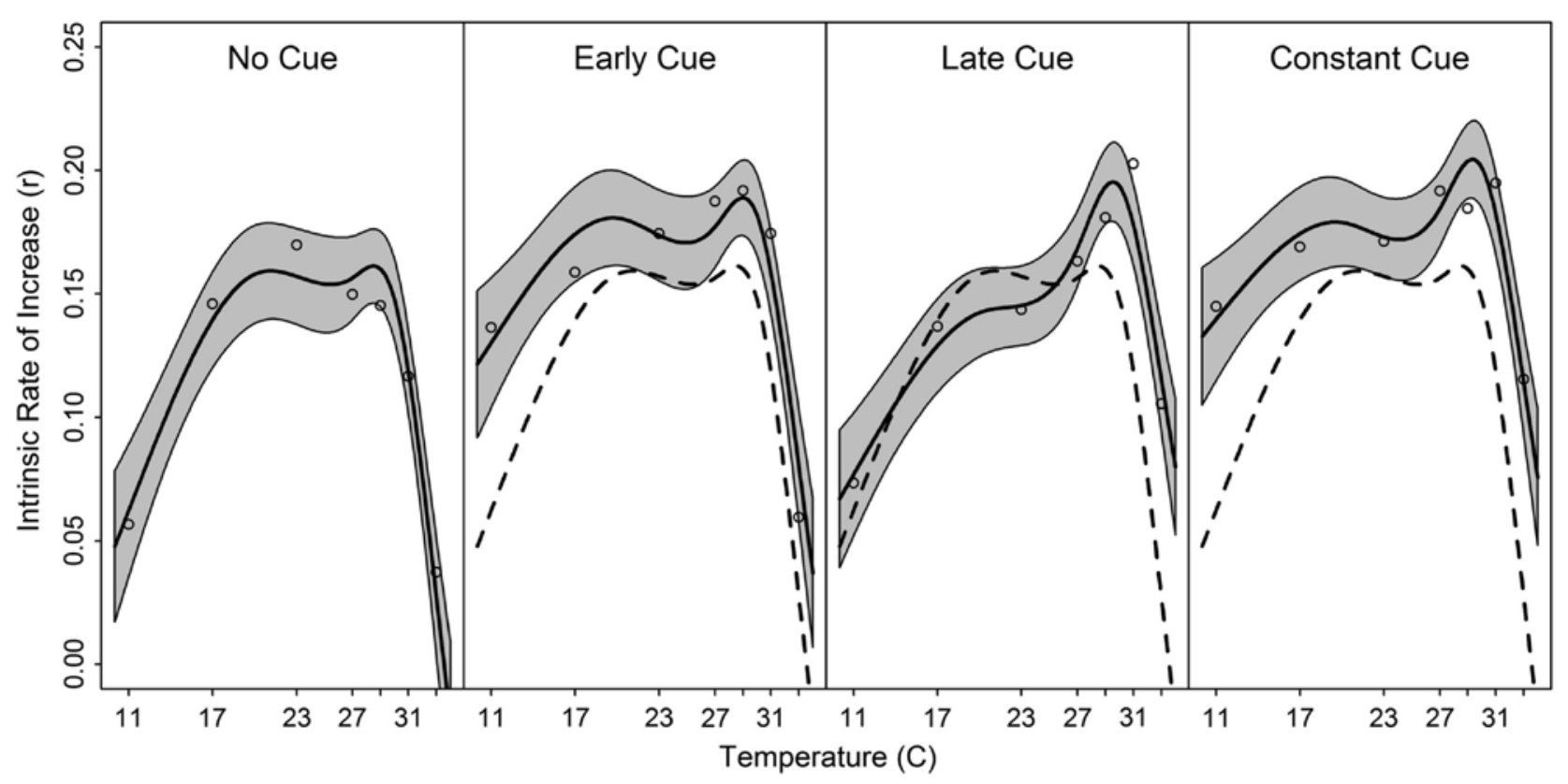

Fig. 4. Temperature dependence of the intrinsic rate of increase, $r$, by predation exposure treatment. Each point depicts the mean of 1000 bootstrapped populations drawn from 10 replicate $D$. magna resampled with replacement. Curves are predicted model fits from a GAM that incorporates both nonlinear temperature effects and treatment-specific temperature curves (GAM constructed from the entire dataset). Predation cues were presented prior to the assay temperature (Early), during the assay temperature (Late), or during both prior to and during the assay temperature (Constant). The fit from the No Cue (control) treatment is provided as a reference (dashed line) on the three treatments receiving predation cues.

treatments $\left(T_{\text {opt }}=29,31\right.$, and $31{ }^{\circ} \mathrm{C}$, respectively). In other words, predation risk at any point in ontogeny shifted $T_{\text {opt }} 6-8{ }^{\circ} \mathrm{C}$ warmer and elevated $r_{\max }$ by $13-19 \%$ relative to the no cue control treatment.

\section{Survival}

Predation treatment and temperature had interactive effects on survivorship (S). At cooler temperatures $\left(11-27^{\circ} \mathrm{C}\right)$, $S$ was uniformly high (Fig. 5). At $29^{\circ} \mathrm{C}$, all control individuals survived (excluded from analyses) and mortality accelerated (relative to cooler temperatures) in predation risk treatments. At $29^{\circ} \mathrm{C}$, individuals in the early exposure treatment died sooner than those in the late $(z=-2.7, P=0.02)$ or constant predation risk $(z=-3.3, P=0.003)$ treatments (Fig. 5). As the 


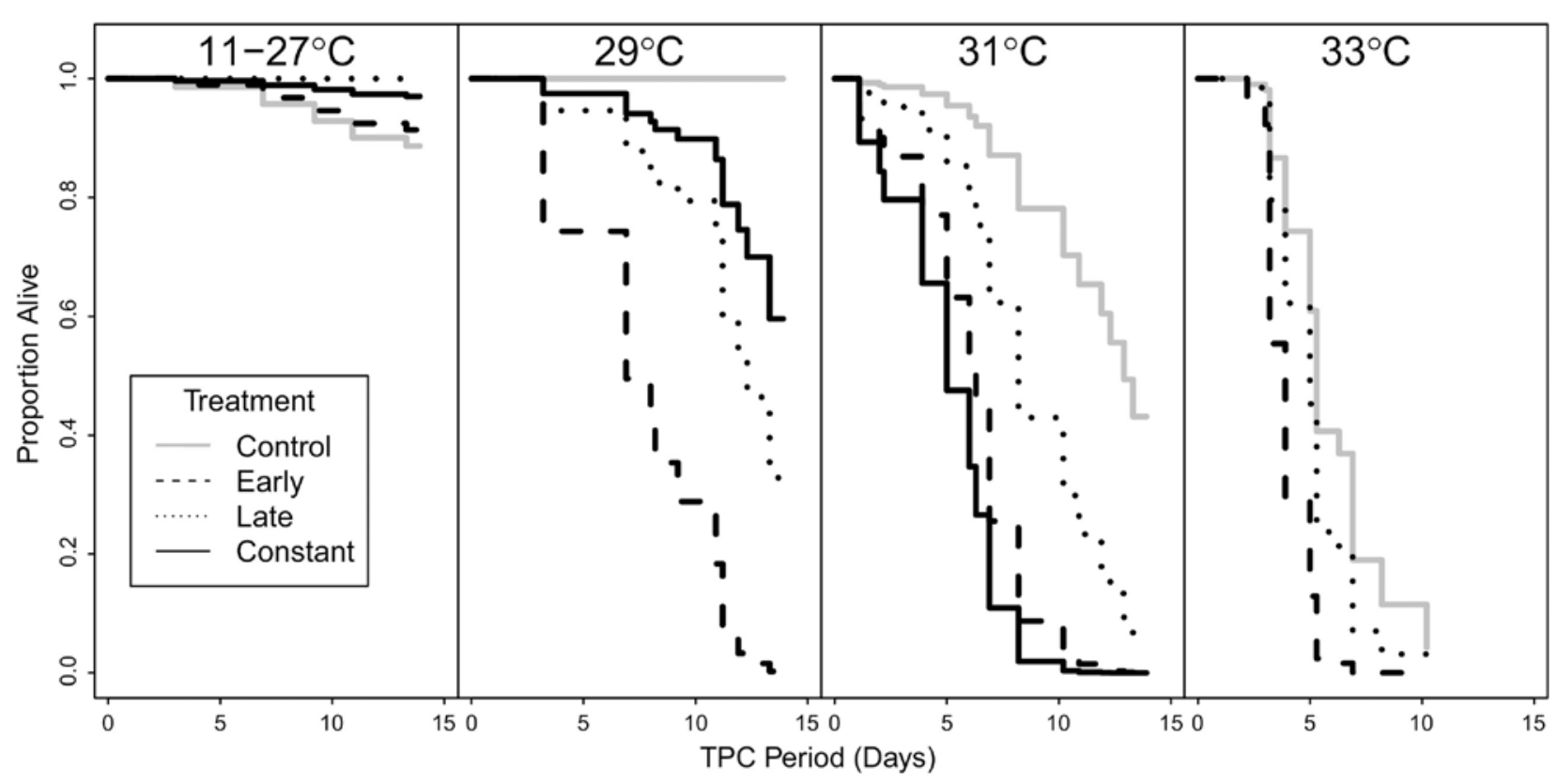

Fig. 5. Survivorship $(S)$ curves (Cox proportional hazard models) for $D$. magna at increasing temperatures (left to right) exposed to predation risk at different times during their ontogeny (treatments) (for each curve $N \sim 10$ ). Survivorship curves are constrained to individual survival from the onset of the TPC period on day 14 when temperature treatments were started. Thus, "Days After Temperature" is the time of exposure to their temperature treatment. Control Daphnia did not experience predation cues. The remainder experienced predation cues during the Natal (Early) or TPC (Late) periods, or throughout the experiment (Constant). At $33^{\circ} \mathrm{C}$, early and constant treatment curves are identical.

temperature reached $31^{\circ} \mathrm{C}$, treatments experiencing predation cues during the natal period showed more rapid mortality curves than the control (early vs. control; $z=3.4, P=0.004$ ) (constant vs. control; $z=$ 4.0, $P<0.001$ ) (Fig. 5). Individuals exposed to predation cues only during the TPC period (late treatment) showed an intermediate response with a higher rate of survival than the constant exposure treatment $(z$ $=2.8, P=0.03$ ) (Fig. 5), but this was statistically indistinguishable from the remaining treatments. At the hottest temperature $\left(33^{\circ} \mathrm{C}\right)$, all individuals died by 10.2 days after the onset of the TPC period. Although mortality was rapid across all treatments at $33^{\circ} \mathrm{C}$, it was accelerated even more in $D$. magna that experienced predation cues during the natal period (relative to the control) in the early $(z=2.7, P=0.04)$ and constant treatments $(z=2.6, P=0.05)$ (Fig. 5). 


\section{Discussion}

Predation risk differentially changed net reproductive rate $\left(R_{0}\right)$, generation time $(T)$ and survival $(S)$ across temperature and ontogeny. Thus, changes in $r$ TPCs emerged from unique and often non-constant changes in life history trait TPCs. For this study, non-constant changes in TPCs indicate that there are temperature-dependent constraints to phenotypically plastic trait change. Classic life history theory predicts that increasing size-independent mortality risk will favor decreased time to maturation (decreasing $T$ ) and increased investment in reproduction (elevating $R_{0}$ ) at the cost of growth or survival (S) (Williams 1966; Roff 1992; Stearns 1992; Ghalambor and Martin 2000). Indeed, we see these patterns in our experiment whereby predation risk decreased $T$, increased $R_{0}$ increased $r$ and was associated with decreased survival at hotter temperatures (Figs. 2, 3, 4, 5). However, the magnitude of phenotypically plastic trait change for any given trait and the potential costs of that change in terms of survival (S) were strongly tied to temperature and timing of exposure to predation cues during ontogeny.

The magnitude of phenotypically plastic trait responses to predation risk showed strong trait-specific effects of temperature and ontogeny. Phenotypically plastic traits vary in their ability to respond across ontogeny (Pigliucci 1998; Hoverman and Relyea 2007), and are sensitive to simultaneous changes in multiple environmental gradients (Relyea 2004). In addition to having different underlying thermal dependences (e.g., $T$ decreases with temperature, $R_{0}$ is unimodal), $R_{0}$ and $T$ responded differentially with respect to temperature and timing of predation risk. Responses of $R_{0}$ to temperature and timing of exposure across ontogeny were consistent with plastic trait induction being hindered at colder temperatures and accelerated at warmer temperatures (later exposure raised $R_{0}$ at hotter but not colder temperatures). Likewise, reversal of trait induction was hindered at colder temperatures (early exposure to predator cues in ontogeny was evident only at colder temperatures). Together, this suggests phenotypically plastic trait changes may be more readily induced and reversed at warmer temperatures. Whereas $R_{0}$ showed temperature-dependent responses to predation risk that varied across ontogeny, changes in $T$ were potentially temperature independent and only detected in $D$. 
magna exposed to predation cues prior to their first clutch. While both $R_{0}$ and $T$ responded to temperature and predation risk, the developmental window for changes in $R_{0}$ appears to be less constrained than that of $T$.

Organisms may also adjust reproductive strategies in response to perceived mortality risk from predation (Magnhagen 1990) and environmental cues (Roitberg et al. 1993). Predation risk alone increased background mortality rates at higher temperatures, potentially because of a tradeoff between survival and reproductive output or an increased survivorship cost in plastic trait changes. Although organisms readily adjust their life histories and behaviors in response to changes in mortality risk from predation (Lima and Dill 1990; Riessen 1999), increases in temperature also elevate mortality rates (Savage et al. 2004; Amarasekare and Savage 2012). Overall mortality increased with temperature, but $D$. magna exposed to predation risk showed increased mortality at temperatures $2^{\circ} \mathrm{C}$ colder than controls (29 vs. $31^{\circ} \mathrm{C}$ ) and died younger than controls across the upper $4{ }^{\circ} \mathrm{C}$ of their TPCs (Fig. 5). However, even though predation risk accelerated mortality at hotter temperatures, it also increased $r$. This is because accelerated mortality rates were outpaced by increases in $R_{0}$ and/or decreases in $T$. Although increased reproductive investment often comes at the cost of survivorship (Stearns 1992), the potential survival cost of increasing reproductive efforts (lowering $T$, increasing $R_{0}$ ) may be minimal compared to the rapidly increasing probability of mortality at hotter temperatures.

Ectotherm fitness $(r)$ TPCs change with ecological context (e.g., acclimation, latitude, predation, nutrients) (Deutsch et al. 2008; Grigaltchik et al. 2012; Seebacher and Grigaltchik 2015; Luhring and DeLong 2016, 2017; Thomas et al. 2017; DeLong et al. 2018). However, changes in $r$ TPCs are ultimately linked to changes in individual traits that have their own reaction norms for temperature and ecological contexts. Thus, a life history approach to understanding how and why $r$ TPCs change is needed to derive robust predictions of how, and how much, lab-derived $r$ TPCs reflect organisms embedded within food webs. For example, warming and size-independent predation risk lead to early maturation at smaller sizes and increase $r$ (Sibly and Atkinson 1994; Riessen 1999; Atkinson et al. 2001) and predation risk generally increased $r$ across temperatures in $D$. magna. 
However, as we show, the response of $r$ and its underlying traits to predation risk changed with temperature and exposure timing. This unequal response to predation risk across temperature points to a potential temperature-dependent constraint on life history strategies (e.g., reproductive allocation, offspring size versus number) (Luhring et al. 2018). In this study, size-independent predation risk increased $r$ consistently at warmer temperatures while its effects at colder temperatures were dependent on whether $D$. magna had experienced predation cues early in ontogeny (Fig. 4). Overall, however, effects of size-independent predation risk cues on $r$ were largely positive and synergistic with the effects of warming. Ecological pressures that lead to delayed maturation (Crowl and Covich 1990; Luhring and Holdo 2015), on the other hand, might be expected to become increasingly in conflict with temperature-dependent processes at warmer temperatures. For example, species under negatively size-dependent predation risk tend to delay reproduction and reach adulthood at larger sizes (Crowl and Covich 1990; Riessen 1999) which would result in responses to temperature and predation risk producing opposing pressures. Likewise, decreased body size at warmer temperatures would potentially increase vulnerability of ectotherms whose ability to withstand environmental disturbances (e.g., drought) is positively correlated with body size (e.g., Luhring and Holdo 2015). These examples highlight the importance of understanding how traits respond to changes in temperature across ecological contexts and the potential limits of phenotypic plasticity.

Changes in $r$ TPCs caused by predation risk in this experiment reflected the complex contributions of life history traits simultaneously responding to temperature and changes in ecological context. The step of linking $r$ TPCs to the actual fitness of organisms in functioning ecosystems faces numerous challenges such as understanding the extent of their plasticity (Sinclair et al. 2016). For $r$, the underlying life history trait responses to ecological contexts of various taxa are well studied (Roff 1992; Stearns 1992; Riessen 1999). Likewise, it is appreciated that phenotypic plasticity should be incorporated into predictions of ectotherm responses to climate change (Riddell et al. 2018). However, our results clearly indicate that phenotypically plastic changes in $r$ TPCs are driven by interacting life history traits with unique responses to temperature, ontogeny, and ecological context. 
Furthermore, the temperature dependence of phenotypic plasticity suggests the capacity of organisms to respond to ecological contexts is constrained by their thermal environment. Thus, not only does temperature directly alter fitness through changes in life history, but also through the rapidity and magnitude of trait responses to the environment.

Acknowledgments - We thank J. Hite for experimental design suggestions, and J. Hotovy, K. Sullivan, S. Tjards, M. Pinto, S. French, B. Bathke, B. Harmon, C. Urbauer, S. Uiterwaal, and R. Vetter for transferring, and counting over 2000 daphnia neonates. We thank AE Scott Peacor, C. Streid, and two anonymous reviewers for their helpful comments on the manuscript. TML thanks the University of Nebraska's Program of Excellence in Population Biology.

Author contributions - TML conceived the study; TML, JMV, CEC, and JPD designed the study; TML and JMV ran the experiment and collected data, TML analyzed the data. TML, JMV, CEC and JPD interpreted the results and TML drafted the manuscript. TML, JMV, CEC, and JPD revised and approved the manuscript. All authors contributed critically to drafts of the manuscript and gave their final approval for publication.

Data accessibility - Data and code available from the Dryad Digital Repository: https://doi.org/10.5061/dryad.bn1sr05

\section{References}

Amarasekare P, Savage V (2012) A framework for elucidating the temperature dependence of fitness. Am Nat 179:178-191. https://doi.org/10.1086/663677

Anderson JT, Inouye DW, McKinney AM et al (2012) Phenotypic plasticity and adaptive evolution contribute to advancing flowering phenology in response to climate change. Proc R Soc B Biol Sci 279:3843-3852. https://doi. org/10.1098/rspb.2012.1051

Angilletta MJ (2009) Thermal adaptation: a theoretical and empirical synthesis. Oxford University Press, Oxford. https://doi.org/10.1093/acprof: oso/9780198570875.001.1

Angilletta MJ, Huey RB, Frazier MR (2010) Thermodynamic effects on organismal performance: is hotter better? Physiol Biochem Zool 83:197-206. https://doi. org/10.1086/648567

Atkinson D, Morley SA, Weetman D, Hughes RN (2001) Offspring size responses to maternal environment in ectotherms: genes, life histories and plasticity. In: Atkinson D, Thorndyke M (eds) Environmental and animal development. Bios Scientific Publishers, Oxford, pp 269-286 
Beckerman AP, Wieski K, Baird DJ (2007) Behavioural versus physiological mediation of life history under predation risk. Oecologia 152:335-343. https:// doi.org/10.1007/s00442-006-0642-6

Beckerman AP, Rodgers GM, Dennis SR (2010) The reaction norm of size and age at maturity under multiple predator risk. J Anim Ecol 79:1069-1076. https://doi. org/10.1111/j.1365-2656.2010.01703.x

Benard MF (2004) Predator-induced phenotypic plasticity in organisms with complex life histories. Annu Rev Ecol Evol Syst 35:651-673. https://doi. org/10.1146/annurev.ecolsys.35.021004.112426

Boersma M, Spaak P, De Meester L (1998) Predator-mediated plasticity in morphology, life history, and behavior of daphnia: the uncoupling of responses. Am Nat 152:237-248. https://doi.org/10.2307/2463487

Brown JH, Gillooly JF, Allen AP et al (2004) Toward a metabolic theory of ecology. Ecology 85:1771-1789. https://doi.org/10.1890/03-9000

Charmantier A, Gienapp P (2014) Climate change and timing of avian breeding and migration: evolutionary versus plastic changes. Evol Appl 7:15-28. https:// doi.org/10.1111/eva.12126

Charmantier A, McCleery RH, Cole LR et al (2008) Adaptive phenotypic plasticity in response to climate change in a wild bird population. Science 320:800-803. https://doi.org/10.1126/science. 1157174

Cox DR (1972) Regression models and life tables. J R Stat Soc Ser B 34:187-220

Crawford BA, Hickman CR, Luhring TM (2012) Testing the threat-sensitive hypothesis with predator familiarity and dietary specificity. Ethology 118:41-48. https://doi.org/10.1111/j.1439-0310.2011.01983.x

Creel S, Christianson D (2008) Relationships between direct predation and risk effects. Trends Ecol Evol 23:194-201. https://doi.org/10.1016/j.tree.2007.12.004

Crowl TA, Covich AP (1990) Predator-induced life-history shifts in a freshwater snail. Science 247:949-951. https://doi.org/10.1126/science.247.4945.949

Culler LE, McPeek MA, Ayres MP (2014) Predation risk shapes thermal physiology of a predaceous damselfly. Oecologia 176:653-660. https://doi.org/10.1007/ s00442-014-3058-8

DeLong JP, Gibert JP, Luhring TM et al (2017) The combined effects of reactant kinetics and enzyme stability explain the temperature dependence of metabolic rates. Ecol Evol 7:3940-3950. https://doi.org/10.1002/ece3.2955

DeLong JP, Bachman G, Gibert JP et al (2018) Habitat, latitude and body mass influence the temperature dependence of metabolic rate. Biol Lett 14:20180442. https://doi.org/10.1098/rsbl.2018.0442

Deutsch CA, Tewksbury JJ, Huey RB et al (2008) Impacts of climate warming on terrestrial ectotherms across latitude. Proc Natl Acad Sci 105:6668-6672. https://doi.org/10.1073/pnas.0709472105

Ernest SKM, Enquist BJ, Brown JH et al (2003) Thermodynamic and metabolic effects on the scaling of production and population energy use. Ecol Lett 6:990-995. https://doi.org/10.1046/j.1461-0248.2003.00526.x 
Ghalambor CK, Martin TE (2000) Parental investment strategies in two species of nuthatch vary with stage-specific predation risk and reproductive effort. Anim Behav 60:263-267. https://doi.org/10.1006/ANBE.2000.1472

Giebelhausen B, Lampert W (2001) Temperature reaction norms of Daphnia magna: the effect of food concentration. Freshw Biol 46:281-289. https://doi. org/10.1046/j.1365-2427.2001.00630.x

Gilchrist GW (1995) Specialists and generalists in changing environments. I. Fitness landscapes of thermal sensitivity. Am Nat 146:252-270. https://doi. org/10.1086/285797

Grigaltchik VS, Ward AJW, Seebacher F (2012) Thermal acclimation of interactions: differential responses to temperature change alter predator-prey relationship. Proc R Soc B Biol Sci 279:4058-4064. https://doi.org/10.1098/rspb.2012.1277

Grigaltchik VS, Webb C, Seebacher F (2016) Temperature modulates the effects of predation and competition on mosquito larvae. Ecol Entomol 41:668-675. https://doi.org/10.1111/een.12339

Hickman CR, Stone MD, Mathis A (2004) Priority use of chemical over visual cues for detection of predators by graybelly salamanders, Eurycea multiplicata griseogaster. Herpetologica 60:203-210. https://doi.org/10.1655/03-26

Hothorn T, Bretz F, Westfall P, Heiberger RM, Schuetzenmeister A, Scheibe S (2017) Simultaneous inference in general parametric models (multcomp). R package version 1.4-7. http://CRAN.Rproject.org/package $=$ multcomp

Hoverman JT, Relyea RA (2007) How flexible is phenotypic plasticity? Developmental windows for trait induction and reversal. Ecology. https://doi. org/10.1890/05-1697

Huey RB, Berrigan D (2001) Temperature, demography, and ectotherm fitness. Am Nat 158:204-210. https://doi.org/10.1086/321314

Katzenberger M, Hammond J, Duarte H et al (2014) Swimming with predators and pesticides: how environmental stressors affect the thermal physiology of tadpoles. PLoS One 9:e98265. https://doi.org/10.1371/journ al.pone.0098265

Kerkhoff AJ, Enquist BJ, Elser JJ, Fagan WF (2005) Plant allometry, stiochiometry and the temperature-dependence of primary productivity. Glob Ecol Biogeogr 14:585-598

Kilham SS, Kreeger DA, Lynn SG et al (1998) COMBO: a defined freshwater culture medium for algae and zooplankton. Hydrobiologia 377:147-159. https://doi. org/10.1023/A:1003231628456

Kingsolver JG (2009) The well-temperatured biologist. Am Nat 174:755-768. https://doi.org/10.1086/648310

Knies JL, Izem R, Supler KL et al (2006) The genetic basis of thermal reaction norm evolution in lab and natural phage populations. PLoS Biol 4:1257-1264. https:// doi.org/10.1371/journal.pbio.0040201

Knies JL, Kingsolver JG, Burch CL (2009) Hotter is better and broader: thermal sensitivity of fitness in a population of bacteriophages. Am Nat 173:419-430. https://doi.org/10.1086/597224 
Kremer CT, Fey SB, Arellano AA, Vasseur DA (2018) Gradual plasticity alters population dynamics in variable environments: thermal acclimation in the green alga Chlamydomonas reinhartdii. Proc R Soc B Biol Sci 285:20171942. https://doi.org/10.1098/rspb.2017.1942

Lima SL, Dill LM (1990) Behavioral decisions made under the risk of predation: a review and prospectus. Can J Zool 68:619-640. https://doi.org/10.1139/ z90-092

Lind J, Cresswell W (2005) Determining the fitness consequences of antipredation behavior. Behav Ecol 16:945-956. https://doi.org/10.1093/behec o/ari075

Luhring TM, DeLong JP (2016) Predation changes the shape of thermal performance curves for population growth rate. Curr Zool 62:501-505. https:// doi.org/10.1093/cz/zow045

Luhring TM, DeLong JP (2017) Scaling from metabolism to population growth rate to understand how acclimation temperature alters thermal performance. Integr Comp Biol 57:103-111. https://doi.org/10.1093/icb/icx041

Luhring TM, Holdo RM (2015) Trade-offs between growth and maturation: the cost of reproduction for surviving environmental extremes. Oecologia 178:723732. https://doi.org/10.1007/s00442-015-3270-1

Luhring TM, Meckley TD, Johnson NS et al (2016) A semelparous fish continues upstream migration when exposed to alarm cue, but adjusts movement speed and timing. Anim Behav 121:41-51. https://doi.org/10.1016/j.anbeh av.2016.08.007

Luhring TM, Vavra JM, Cressler CE, DeLong JP (2018) Predators modify the temperature dependence of life-history trade-offs. Ecol Evol 8:8818-8830. https://doi.org/10.1002/ece3.4381

Lynch M, Gabriel W (1987) Environmental Tolerance. Am Nat 129:283-303. https://doi.org/10.1086/284635

Magnhagen C (1990) Reproduction under predation risk in the sand goby, Pomatoschistus minutes, and the black goby, Gobius niger: The effect of age and longevity. Behav Ecol Sociobiol 26:331-335. https://doi.org/10.1007/ $\underline{B F 00171098}$

Novich RA, Erickson EK, Kalinoski RM, DeLong JP (2014) The temperature independence of interaction strength in a sit-and-wait predator. Ecosphere 5:art137. https://doi.org/10.1890/es14-00216.1

Padfield D, Yvon-Durocher G, Buckling A et al (2016) Rapid evolution of metabolic traits explains thermal adaptation in phytoplankton. Ecol Lett 19:133-142. https://doi.org/10.1111/ele.12545

Pangle KL, Peacor SD, Johannsson OE (2007) Large nonlethal effects of an invasive invertebrate predator on zooplankton population growth rate. Ecology 88:402412. https://doi.org/10.1890/06-0768

Parmesan C (2006) Ecological and evolutionary responses to recent climate change. Annu Rev Ecol Evol Syst 37:637-669. https://doi.org/10.2307/annurev. ecolsys.37.091305.30000024 
Pigliucci M (1998) Developmental phenotypic plasticity: where internal programming meets the external environment. Curr Opin Plant Biol 1:87-91. https://doi.org/10.1016/S1369-5266(98)80133-7

Poloczanska ES, Brown CJ, Sydeman WJ et al (2013) Global imprint of climate change on marine life. Nat Clim Chang 3:919-925. https://doi.org/10.1038/ Nclimate1958

R Core Team (2018). R: a language and environment for statistical computing. R foundation for statistical computing, Vienna, Austria. https://www.R-project. org/

Reale D, McAdam AG, Boutin S, Berteaux D (2003) Genetic and plastic responses of a northern mammal to climate change. Proc R Soc B Biol Sci 270:591-596. https://doi.org/10.1098/rspb.2002.2224

Reede T (1995) Life history shifts in response to different levels of fish kairomones in Daphnia. J Plankton Res. https://doi.org/10.1093/plankt/17.8.1661

Relyea RA (2004) Fine-tuned phenotypes: tadpole plasticity under 16 combinations of predators and competitors. Ecology. https://doi. org/10.1890/03-0169

Reznick D, Endler JA (1982) The impact of predation on life history evolution in Trinidadian guppies (Poecilia reticulata). Evolution (N Y) 36:160-177. https:// doi.org/10.2307/2407978

Riddell EA, Odom JP, Damm JD, Sears MW (2018) Plasticity reveals hidden resistance to extinction under climate change in the global hotspot of salamander diversity. Sci Adv 4:eaar5471. https://doi.org/10.1126/sciadv. aar5471

Riessen HP (1999) Predator-induced life history shifts in Daphnia: a synthesis of studies using meta-analysis. Can J Fish Aquat Sci 56:2487-2494. https://doi. org/10.1139/cjfas-56-12-2487

Roff DA (1992) The evolution of life histories: theory and analysis. Chapman and Hall, New York

Roitberg BD, Sircom J, Roitberg CA, van Alphen JJ, Mangel M (1993) Life expectancy and reproduction. Nature 364:108

Sakwińska O (1998) Plasticity of Daphnia magna life history traits in response to temperature and information about a predator. Freshw Biol. https://doi. org/10.1046/j.1365-2427.1998.00320.x

Savage VM, Gillooly JF, Brown JH et al (2004) Effects of body size and temperature on population growth. Am Nat 163:429-441. https://doi.org/10.1086/381872

Schaum C-E, Barton S, Bestion E et al (2017) Adaptation of phytoplankton to a decade of experimental warming linked to increased photosynthesis. Nat Ecol Evol 1:0094. https://doi.org/10.1038/s4155 9-017-0094

Schulte PM, Healy TM, Fangue NA (2011) Thermal performance curves, phenotypic plasticity, and the time scales of temperature exposure. Integr Comp Biol 51:691-702. https://doi.org/10.1093/icb/icr097

Seebacher F, Grigaltchik VS (2015) Developmental thermal plasticity of prey modifies the impact of predation. J Exp Biol 218:1402- 1409. https://doi. org/10.1242/jeb. 116558 
Seebacher F, White CR, Franklin CE (2015) Physiological plasticity increases resilience of ectothermic animals to climate change. Nat Clim Chang 5:61-66. https://doi.org/10.1038/nclimate2457

Sibly RM, Atkinson D (1994) How rearing temperature affects optimal adult size in ectotherms. Funct Ecol 8:486-493. https://doi.org/10.2307/2390073

Sinclair BJ, Marshall KE, Sewell MA et al (2016) Can we predict ectotherm responses to climate change using thermal performance curves and body temperatures? Ecol Lett 19:1372-1385

Stearns SC (1992) The evolution of life histories. Oxford University Press, New York Stibor H (1992) Predator induced life-history shifts in a freshwater cladoceran. Oecologia 92:162-165. https://doi.org/10.1007/BF00317358

Stibor H, Luning J (1994) Predator-induced phenotypic variation in the pattern of growth and reproduction in Daphnia hyalina (Crustacea: Cladocera). Funct Ecol 8:97-101. https://doi.org/10.2307/2390117

Therneau TM, Lumley T (2017) Survival: survival analysis. R package version 2.413. http://CRAN.R-project.org/package=survival

Thomas MK, Aranguren-Gassis M, Kremer CT et al (2017) Temperature- nutrient interactions exacerbate sensitivity to warming in phytoplankton. Glob Chang Biol 23:3269-3280. https://doi.org/10.1111/gcb.13641

Tolon V, Dray S, Loison A et al (2009) Responding to spatial and temporal variations in predation risk: space use of a game species in a changing landscape of fear. Can J Zool 87:1129-1137. https://doi.org/10.1139/Z09-101

Tseng M, O'Connor MI (2015) Predators modify the evolutionary response of prey to temperature change. Biol Lett 11:20150798. https://doi.org/10.1098/ rsbl.2015.0798

Van Buskirk J, Schmidt BR (2000) Predator-induced phenotypic plasticity in larval newts: trade-offs, selection, and variation in nature. Ecology 81:3009-3028. https://doi.org/10.2307/177397

Vasseur DA, DeLong JP, Gilbert B et al (2014) Increased temperature variation poses a greater risk to species than climate warming. Proc R Soc B Biol Sci 281:20132612. https://doi.org/10.1098/rspb.2013.2612

Walsh MR, Cooley F, Biles K, Munch SB (2014) Predator-induced phenotypic plasticity within- and across-generations: a challenge for theory? Proc R Soc $B$ Biol Sci 282:20142205. https://doi.org/10.1098/rspb.2014.2205

Walther GR, Post E, Convey P et al (2002) Ecological responses to recent climate change. Nature 416:389-395. https://doi.org/10.1038/416389a

Williams GC (1966) Natural selection, the costs of reproduction, and a refinement of lack's principle. Am Nat 100:687-690. https://doi.org/10.1086/282461

Wood SN (2006) Generalized additive models: an introduction with R. Chapman and Hall/CRC Press, Boca Raton, FL

Wood SN (2015) Package 'mgcv'. R package version 1.8-7. http://CRAN.R-project. org/package $=$ mgcv

Zanette LY, White AF, Allen MC, Clinchy M (2011) Perceived predation risk reduces the number of offspring songbirds produce per year. Science 334:1398-1401. https://doi.org/10.1126/science. 1210908 


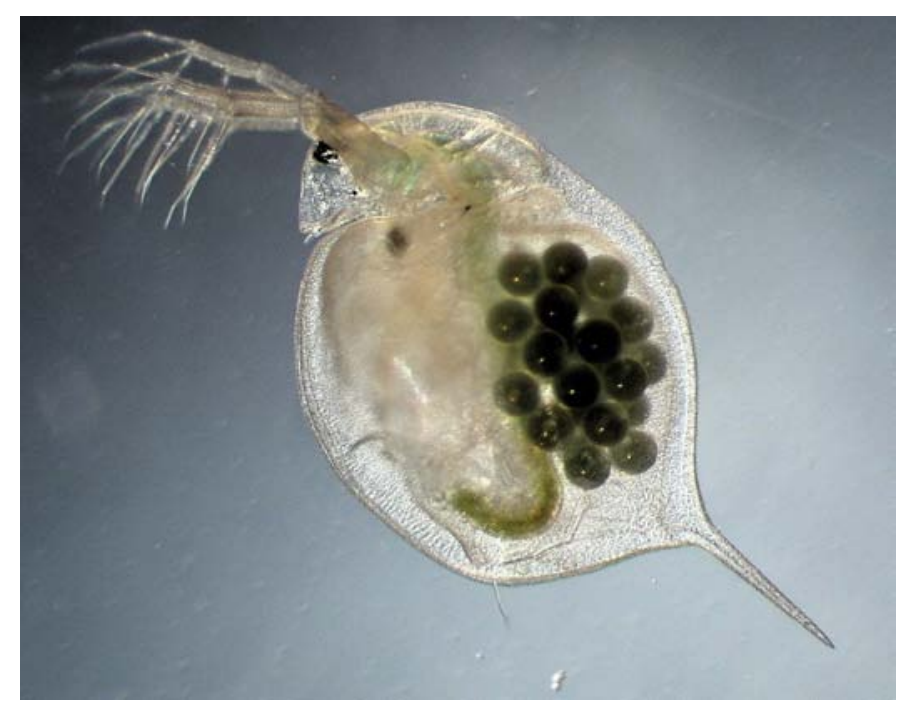

Female Daphnia magna with a clutch of asexual eggs. The animal is about $4 \mathrm{~mm}$ long. Dieter Ebert, Basel, Switzerland. CC-BY-SA

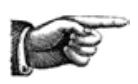

Supplementary material follows. 
Phenotypically plastic responses to predation risk are temperature dependent.

Thomas M. Luhring ${ }^{1 *}$, Janna M. Vavra ${ }^{1}$, Clayton E. Cressler ${ }^{1}, \&$ John P. DeLong ${ }^{1}$.

${ }^{1}$ School of Biological Sciences, University of Nebraska - Lincoln, Nebraska 68588

*410 Manter Hall, University of Nebraska, Lincoln, Nebraska 68588

*e-mail: tomluhring@gmail.com

\section{Keywords}

Climate Change, Fecundity, Life History, Mortality, Reproduction, Survivorship

\section{Electronic Supplementary Material (ESM)}

Table S1 Summary table of parametric and smooth terms, and parametric coefficient estimates for generalized additive models (GAMs). Statistically significant terms are bolded $(P<0.05)$ 


\begin{tabular}{|c|c|c|c|c|c|}
\hline Response & Parametric Terms & & $d f$ & $\boldsymbol{F}$ & $\boldsymbol{P}$ \\
\hline \multirow[t]{12}{*}{$r$} & Treatment & & 3 & 14.9 & $<0.001$ \\
\hline & Smooth Terms & & Ref. $d f$ & $\boldsymbol{F}$ & $\boldsymbol{P}$ \\
\hline & Temperature & & 3.8 & 27.1 & $<0.001$ \\
\hline & Temp:Control & & 1.8 & 7.5 & 0.005 \\
\hline & Temp:Early & & 1.7 & 2.2 & 0.087 \\
\hline & Temp:Late & & 0.8 & 17.9 & 0.002 \\
\hline & Temp:Constant & & 0.8 & 0.5 & 0.535 \\
\hline & $\begin{array}{l}\text { Parametric } \\
\text { Coefficients }\end{array}$ & Est & $S E$ & $t$ & $\boldsymbol{P}$ \\
\hline & Intercept & 0.12 & 0.01 & 21.2 & $<0.001$ \\
\hline & Early & 0.04 & 0.01 & 4.8 & $<0.001$ \\
\hline & Late & 0.03 & 0.01 & 3.4 & 0.004 \\
\hline & Constant & 0.05 & 0.01 & 6.4 & $<0.001$ \\
\hline Response & Parametric Terms & & $d f$ & $\boldsymbol{F}$ & $\boldsymbol{P}$ \\
\hline \multirow[t]{12}{*}{$\boldsymbol{R}_{0}$} & Treatment & & 3 & 7.2 & 0.002 \\
\hline & Smooth Terms & & Ref. $d f$ & $\boldsymbol{F}$ & $\boldsymbol{P}$ \\
\hline & Temperature & & 1.8 & 70.4 & $<0.001$ \\
\hline & Temp:Control & & 0.8 & 0.2 & 0.692 \\
\hline & Temp:Early & & 0.8 & 5.9 & 0.042 \\
\hline & Temp:Late & & 0.8 & 7.1 & 0.028 \\
\hline & Temp:Constant & & 1.7 & 2.0 & 0.112 \\
\hline & $\begin{array}{l}\text { Parametric } \\
\text { Coefficients }\end{array}$ & Est & $S E$ & $t$ & $\boldsymbol{P}$ \\
\hline & Intercept & 11.17 & 0.98 & 11.3 & $<0.001$ \\
\hline & Early & 2.18 & 1.39 & 1.6 & 0.135 \\
\hline & Late & 1.75 & 1.39 & 1.3 & 0.223 \\
\hline & Constant & 6.24 & 1.39 & 4.5 & $<0.001$ \\
\hline Response & Parametric Terms & & $d f$ & $\boldsymbol{F}$ & $\boldsymbol{P}$ \\
\hline \multirow[t]{12}{*}{$T$} & Treatment & & 3 & 4.3 & 0.019 \\
\hline & Smooth Terms & & Ref. $d f$ & $\boldsymbol{F}$ & $\boldsymbol{P}$ \\
\hline & Temperature & & 1.8 & 44.4 & $<0.001$ \\
\hline & Temp:Control & & 0.8 & 4.1 & 0.087 \\
\hline & Temp:Early & & 0.8 & 5.0 & 0.060 \\
\hline & Temp:Late & & 1.6 & 0.6 & 0.402 \\
\hline & Temp:Constant & & 1.7 & 2.3 & 0.114 \\
\hline & $\begin{array}{l}\text { Parametric } \\
\text { Coefficients }\end{array}$ & Est & $S E$ & $t$ & $P$ \\
\hline & Intercept & 16.96 & 0.51 & 33.2 & $<0.001$ \\
\hline & Early & -2.28 & 0.72 & -3.2 & 0.006 \\
\hline & Late & -0.46 & 0.72 & -0.6 & 0.536 \\
\hline & Constant & -1.68 & 0.72 & -2.3 & 0.033 \\
\hline
\end{tabular}

